CASE REPORTS

\title{
Hereditary motor and sensor neuropathy: a cause of acute stridor
}

\section{T Jaiganesh, A Bentley}

Emerg Med J 2005;22:666-667. doi: 10.1136/emj.2003.009886

We present an acute stridor secondary to bilateral vocal cord paresis in a patient with demyelinating form (type I) of hereditary motor and sensory neuropathy (HMSN). Management problems are discussed and HMSN reviewed.

A 48 year old female attended the emergency department with complaints of cough, breathing difficulty, and flu-like symptoms for one day. She suffers from hereditary motor and sensory neuropathy (HMSN) Type Ia, which had been detected by isolating DNA from a blood sample for the presence of duplication on Chromosome 17. She had been treated for asthma for two years and had a history of nocturnal choking episodes. Examination revealed inspiratory stridor with indrawing of neck muscles. The ear, nose, and throat (ENT) surgeons, consultant anaesthetist, and intensivist were contacted. ENT examination through a fibre optic flexible laryngoscope revealed smooth white paramedian position of the vocal cords, which were not swollen. Neurological examination revealed peripheral lower motor neurone (LMN) wasting of the arm and legs distally with areflexia. Family history was suggestive of an autosomal dominant pattern of inheritance. There was no evidence of diaphragmatic or respiratory muscle weakness.

She was transferred to theatre recovery suite and had a gaseous induction for endotracheal intubation. Further inspection of the vocal cords confirmed they were partially adducted. The patient was intubated and subsequently transferred to the intensive care unit (ICU). Forty eight hours later she went to theatre for an examination of vocal cords using a flexible laryngoscope prior to consideration of extubation. The vocal cords remained in paramedian position and were now oedematous. She therefore underwent a formal tracheostomy and returned to ICU where she was weaned and was discharged home with tracheostomy in situ with an early follow up to the regional neuromuscular clinic.

\section{DISCUSSION}

HMSN, previously known as charcot marie tooth (CMT) disease or peroneal muscular atrophy (PMA), was initially described in 1868 by two French neurologists (Charcot and Marie) $)^{1}$ and one English neurologist (Tooth) ${ }^{2}$ as a familial condition causing distal muscular atrophy. HMSN is a slowly progressive genetic disorder, which causes deterioration of the peripheral nerves resulting in weakness and sensory loss of the distal limbs. There are a few identified cases that involve the vocal cords and/or the respiratory muscles, particularly the diaphragm (table 1).

Cranial nerves can be involved in the pathological process of HMSN. In a cohesive overview only 11 cases of HMSN with
Table 1 Clinical presentation of HMSN related to the genetic defects

\begin{tabular}{|c|c|c|c|c|}
\hline Type & $\begin{array}{l}\text { Chromo- } \\
\text { some }\end{array}$ & $\begin{array}{l}\text { Age of } \\
\text { onset (in } \\
\text { years) }\end{array}$ & $\begin{array}{l}\text { Early } \\
\text { symptoms }\end{array}$ & $\begin{array}{l}\text { Tendon } \\
\text { reflexes }\end{array}$ \\
\hline \multicolumn{5}{|l|}{$\begin{array}{l}\text { HMSN 1: dominant; } \\
\text { demyelinating }\end{array}$} \\
\hline $1 \mathrm{~A}$ & 17 & $5-10$ & $\begin{array}{l}\text { Distal } \\
\text { weakness }\end{array}$ & Absent \\
\hline $1 \mathrm{~B}$ & 1 & $5-10$ & $\begin{array}{l}\text { Distal } \\
\text { weakness }\end{array}$ & Absent \\
\hline $1 \mathrm{C}$ & Unknown & $10-15$ & $\begin{array}{l}\text { Distal } \\
\text { weakness }\end{array}$ & Reduced \\
\hline 1D & 10 & $10-15$ & $\begin{array}{l}\text { Distal } \\
\text { weakness }\end{array}$ & Absent \\
\hline 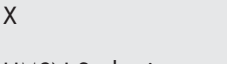 & $x$ & $10-15$ & $\begin{array}{l}\text { Distal } \\
\text { weakness }\end{array}$ & Absent \\
\hline \multicolumn{5}{|l|}{$\begin{array}{l}\text { HMSN 2: dominant; } \\
\text { axonal }\end{array}$} \\
\hline $2 \mathrm{~A}$ & 1 & 10 & $\begin{array}{l}\text { Distal } \\
\text { weakness }\end{array}$ & Absent \\
\hline $2 B$ & 3 & $10-20$ & $\begin{array}{l}\text { Distal } \\
\text { weakness } \\
\text { Sensory loss }\end{array}$ & Absent \\
\hline $2 \mathrm{C}$ & Unknown & $\begin{array}{l}1^{\text {st }} \\
\text { decade }\end{array}$ & $\begin{array}{l}\text { Vocal cord } \\
\text { \& distal } \\
\text { weakness }\end{array}$ & Absent \\
\hline $2 \mathrm{D}$ & 7 & $16-30$ & $\begin{array}{l}\text { Distal } \\
\text { weakness }\end{array}$ & Reduced \\
\hline $\begin{array}{l}\text { HMSN } 3 \text { (Dejerine- } \\
\text { Sottas) } \\
\text { HMSN 4: recessive; } \\
\text { demyelinating/axonal } \\
\text { Involves ethnic groups }\end{array}$ & & 2 years & $\begin{array}{l}\text { Severe } \\
\text { weakness }\end{array}$ & Absent \\
\hline
\end{tabular}

bilateral vocal cord paresis have been observed and of that only two have occurred in type I. $^{3}$ Vocal cord and diaphragm involvement is usually a feature of type IIc. ${ }^{4}$ Most of the patients with HMSN tolerate vocal cord paresis remarkably well but can result in quick rapid decompensation, as shown in our case, possibly related to inter-current infection. The patient's mother also suffered from a similar condition and her son is currently suffering from a the same condition, supporting autosomal dominant inheritance, but none of them have developed stridor. This is possibly because there may be some re-innervation and recovery of function.

Vocal cord paresis in HMSN is most often bilateral and is not restricted to type IIc as was previously thought. Vocal cord paresis may be overlooked or misdiagnosed as asthma, as in our patient. The small number of cases with

Abbreviations: CMT, charcot marie tooth; ENT, ear, nose, and throat; HMSN, hereditary motor and sensory neuropathy; ICU, intensive care unit; PMA, peroneal muscular atrophy 
tracheostomy in children suggests that in adults there may be a partial recovery. In our case this will be reviewed in the regional neuromuscular clinic.

\author{
Authors' affiliations \\ T Jaiganesh, A Bentley, Intensive Care Unit, North Manchester General \\ Hospital, Delaunays Road, Crumpsall, Manchester M8 6RB \\ Competing interests: none declared
}

Correspondence to: Dr A M Bentley, Ventilatory Support Unit, Wythenshawe Hospital, Southmoor Road, Manchester, M23 9LT; bemplex@aol.com
Received 24 July 2003

In revised form 15 December 2003

Accepted for publication 15 December 2003

\section{REFERENCES}

1 Charcot JM, Marie P. On a specific form of frequently familial progressive muscular atrophy beginning in the feet and legs and later affecting the hands (in French). Rev Med 1886;6:97-138.

2 Tooth $\mathbf{H}$. The peroneal type of progressive muscular atrophy. London: Lewis HK Publishers, 1886.

3 Sulcia L, Blitzer A, Lovelace RE, et al. Vocal fold paresis of charcot-marie-tooth disease. Ann Otol Rhinol Laryngol 2001;110:1072-76.

4 Dyck PJ, Litchy WJ, Minnerath S, et al. Hereditary motor and sensory neuropathy with diaphragm and vocal cord paresis. Ann Neurol 1994;35:608-15.

\section{Recurrent elbow dislocation - an uncommon presentation}

\section{Sunderamoorthy, A Smith, D A Woods}

Emerg Med J 2005;22:667-669. doi: 10.1136/emj.2003.013557

A 58 year old female attended our A\&E department following a fall in the garden with swelling and bruising of the right arm and the elbow. Anteroposterior and lateral radiographs were interpreted as showing a normal elbow joint. A diagnosis of soft tissue injury to the elbow was made and the patient was discharged with advice. She returned 2 days later, did not have an $x$ ray, and again given advice. Three weeks later she was referred back to A\&E by the general practitioner with persistent swelling of the elbow. Further radiographs showed a posterolateral dislocation of the elbow. The elbow was reduced under sedation but was subsequently dislocated at follow up, and was treated by external fixator and transolecranon pin. The fixator was removed at 4 weeks and the elbow was then stable. This case highlights that recurrent elbow dislocations due to significant ligament injuries can present in joint and subsequently dislocate. A high index of suspicion is necessary and appropriate referral to the specialist must be made to avoid the morbidity associated with recurrent dislocation. It also emphasises the need to always assess the patient on his or her own merits despite previously normal investigations.

T he elbow is one of the more highly constrained and stable joints in the body, yet dislocation is not uncommon. ${ }^{12}$ Because of its intrinsic stability, redislocation is rare in the elbow in contrast to the shoulder. Most acute elbow dislocations are posterior. There are no previous reports in the literature of a recurrent elbow dislocation presenting as a normal elbow and subsequently dislocating. We describe the management of this patient, highlight the lessons learnt, and describe best practice for similar cases.

\section{CASE REPORT}

A 58 year old female presented to the accident and emergency (A\&E) department with extensive bruising and swelling of the right arm and the elbow following a fall in the garden. The elbow movements were restricted with no distal neurovascular deficit. Anteroposterior and lateral radiograph

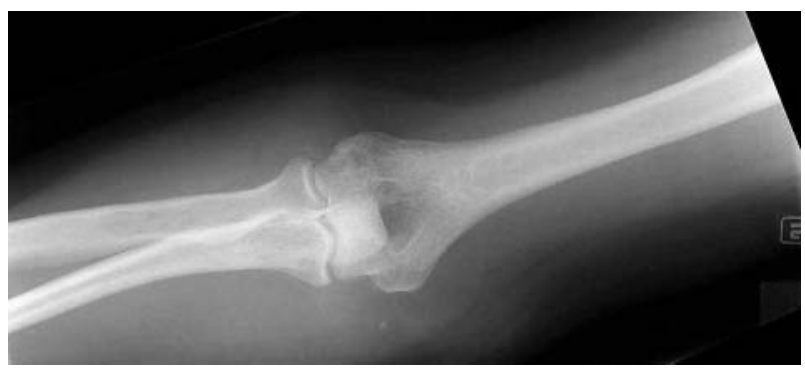

Figure 1 Anteroposterior radiograph of elbow at initial presentation. Reproduced with permission.

of the elbow was interpreted as normal and the patient was discharged with analgesics and limb elevation advice (figs 1 and 2). The patient returned to the A\&E 2 days later with increasing pain and deformity. She was advised that the management plan was correct as the initial radiograph showed no dislocation.

Three weeks later the general practitioner referred the patient to the on call orthopaedic doctor because of continued pain and swelling. On examination the elbow was still swollen with a restricted range of movement. Radiographs of the elbow were repeated, which showed a posterolateral dislocation of the elbow (figs 3 and 4). The elbow was reduced in the A\&E department and referred to the fracture clinic. At two weeks review in the clinic, the elbow had dislocated again. Subsequent treatment involved examination under anaesthesia (EUA) in the theatre where the elbow was found to be grossly unstable; after application of external fixator and transolecranon pin (fig 5), which was removed at 4 weeks, the elbow was found to be stable. There had been no further dislocation and the patient was referred to the physiotherapy department for mobilisation of the elbow. At four months review the elbow was stable with an extension loss of about $30^{\circ}$.

Abbreviations: A\&E, accident and emergency; EUA, examination under anaesthesia 


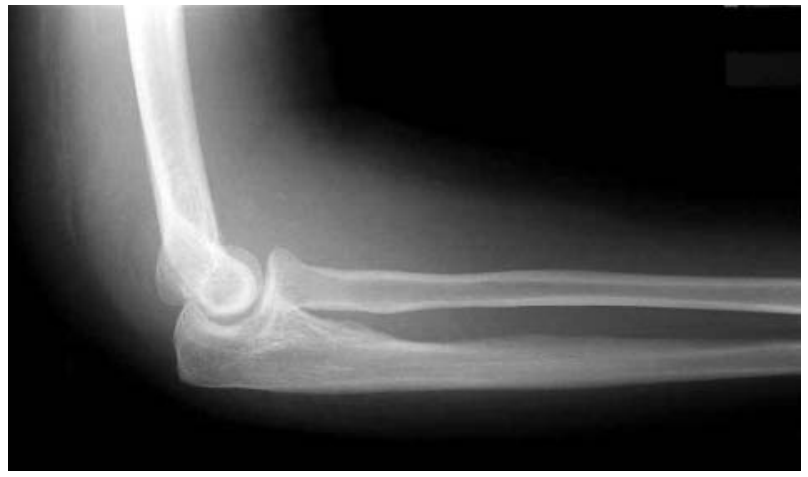

Figure 2 Lateral radiograph of elbow at initial presentation. Reproduced with permission.

\section{DISCUSSION}

Recurrent instability of the elbow joint is uncommon but it is a debilitating disorder when present. The elbow is the second most commonly dislocated large joint after the shoulder in adults and the most common in children. ${ }^{2}$ Recurrent dislocation is an uncommon sequelae. It usually occurs in association with intra-articular fracture or generalised ligament laxity, but can occur following simple dislocation. ${ }^{23}$ We can find no mention in the literature of an elbow dislocating two days after the index injury, when at initial presentation the elbow was found to be in joint.

The elbow is a highly constrained joint and the stability depends on the bony architecture and the integrity of the ligaments, capsule, and muscles around the joint. The articular surface of the elbow is congruent and the bony surfaces minimise the risk of dislocation. The medial and lateral collateral ligaments are strong and play an important role in the stability of the joint. Theories on the most important factors in the stability of the joint have changed over 20 years. ${ }^{4}$ The medial collateral ligament was believed to be the important stabiliser and posterolateral dislocation was not possible if the medial collateral ligament remained intact. ${ }^{5}$ Recently attention has focussed on the lateral ulnar collateral ligament as the primary constraint to posterolateral instability ${ }^{6}$ and the secondary constraints of the extensor muscle origin, fascial bands, and lateral intermuscular septum. ${ }^{7}$

Elbow instability may be classified by time (acute, chronic, or recurrent), by direction (medial, lateral, posterolateral, or anterior), by associated injuries (fracture of the coronoid, radial head, capitellum, medial and lateral epicondyle, disrupted proximal radio-ulnar joint), or by mechanism of injury (hyperextension, axial compression, valgus and supination, or valgus stress).

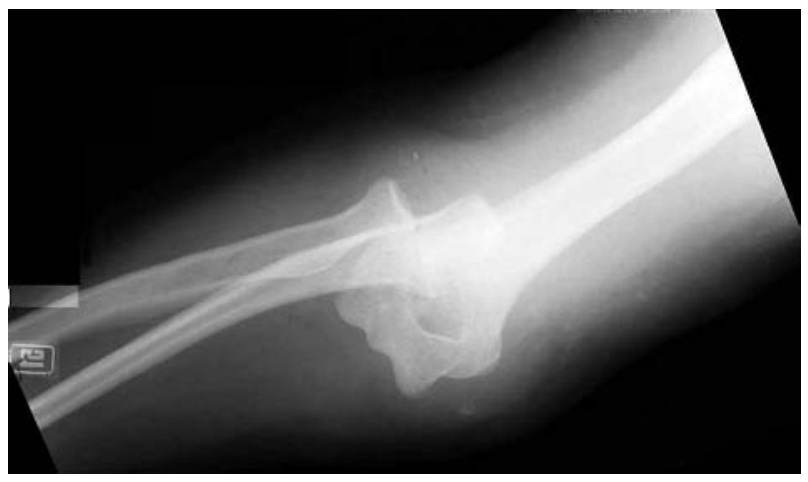

Figure 3 Anteroposterior radiograph of the dislocated elbow. Reproduced with permission.

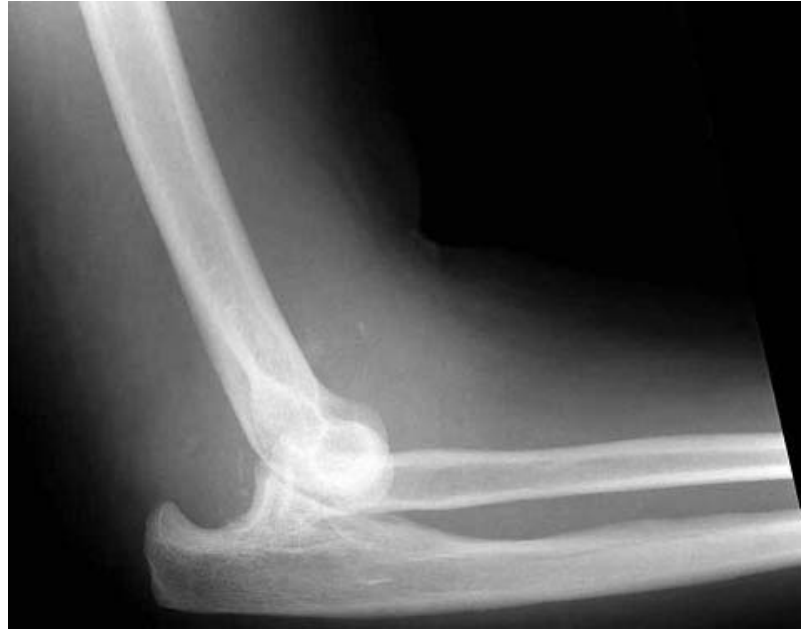

Figure 4 Lateral radiograph of the dislocated elbow. Reproduced with permission.

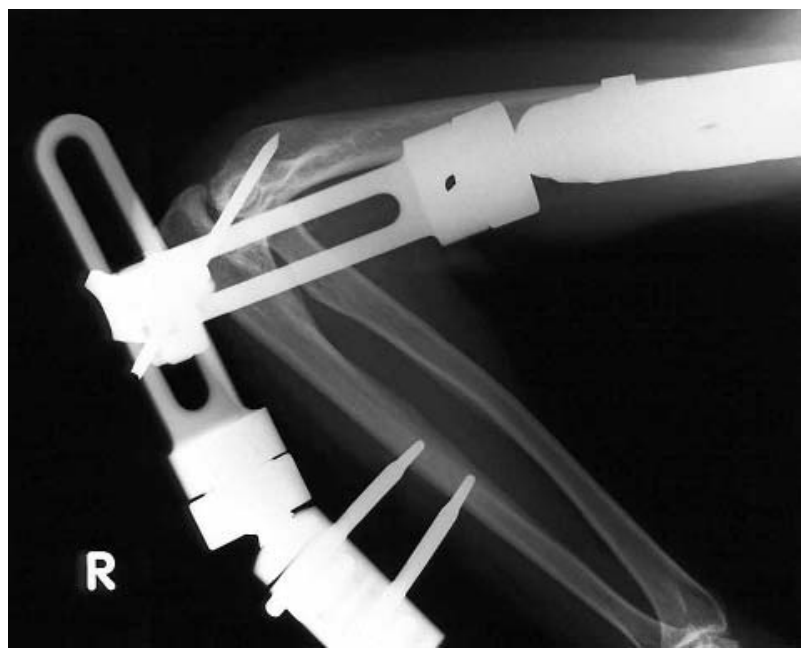

Figure 5 Radigraph of the elbow treated with external fixator and transolecranon pin. Reproduced with permission.

Clinical evaluation includes careful history of the injury and the events causing instability and examination, including the valgus stress test and the posterolateral instability test. ${ }^{6}$ Routine anteroposterior and lateral radiographs may reveal associated bony injuries, degenerative changes, and heterotrophic bone around the elbow. In posterolateral rotatory instability, the lateral view with the forearm supinated may show widening of the humero-ulanr joint with inferior subluxation of the radial head.

Magnetic resonance imaging and computed tomography arthrogram may be used to identify ligamentous injuries. ${ }^{8}$ EUA may be indicated when the history is convincing or the clinical examination unhelpful.

\section{LESSONS LEARNT AND BEST PRACTICE}

Our patient had clearly suffered a significant ligamentous injury, which allowed the elbow to dislocate, reduce spontaneously, and then subsequently redislocate. This case highlights that recurrent elbow dislocations can present in joint. Although the initial radiographs showed that the elbow was not dislocated, careful scrutiny of the radiographs retrospectively showed tiny bony avulsions from the medial and lateral epicondyles. This suggested that the elbow had 
sustained significant ligament injury, which may predispose to recurrent instability. This needs to be specifically noted on the initial $x$ rays. The subsequent attendance two days later was documented as showing deformity of the elbow. The mistake was in assuming that the patient's condition remained the same and that there was no need to re-evaluate the situation and take more $x$ rays. The elbow was almost certainly dislocated at this stage. It emphasises the need to assess the patient on his or her own merits despite previously normal investigations.

Once the elbow was found to be dislocated at three weeks, a reduction in theatre would have been more appropriate as an EUA at this stage would have revealed the gross instability and a stabilising procedure could have been performed forthwith. Finally, the patient was referred to the fracture clinic with a two week appointment. All dislocated joints should be seen at the next available clinic, no more than a few days from the injury, to ensure that the relocated joint remains in place.

\section{Authors' affiliations}

D Sunderamoorthy, Senior House Officer in Orthopaedics, Princess Margaret Hospital, Swindon, SNI 4JU, UK

A Smith, Previously Registrar in Orthopaedics, Princess Margaret Hospital, Swindon, SNI 4JU, UK
D A Woods, Consultant Orthopaedic Surgeon, Great Western Hospital, Swindon, SN3 6BB, UK

Competing interests: none declared

Correspondence to: D Sunderamoorthy, Senior House Officer in Orthopaedics, 4 Lakeside Gardens, Merthyr Tydfil, CF48 1EN, UK; dsundar6@hotmail.com

Accepted for publication 22 March 2004

\section{REFERENCES}

1 Linscheid RL, Wheeler DK. Elbow dislocations. JAMA 1965;194:113-18.

2 Osbourne G, Cotterill P. Recurrent dislocation of the elbow. J Bone Joint Surg 1966;48(B):340-6.

3 Jacobs RL. Recurrent dislocation of the elbow. A case report and a review of the literature. Clin Ortho 1971;74:151-4.

4 Woods DA. Chronic instability of the elbow. In: Bulstrode C, et al, eds. Oxford Textbook of Orthopaedics and Trauma. Oxford: Oxford University Press, 2002; Ch 2.2.13, 772-81.

5 Schwab GH, Bennett JB, Woods GW, et al. Biomechanics of elbow instability: the role of medial collateral ligament. Clin Ortho 1980;146:42-52.

$6 \mathrm{O}^{\prime}$ Driscoll SW, Bel DF, Morrey BF. Posterolateral rotatory instability of the elbow. J Bone Joint Surg 1991;73(A):440-6.

7 Cohen MS, Hastings $\mathrm{H}$. Rotatory instability of the elbow. The anatomy and role of the lateral stabilisers. J Bone Joint Surg 1997;79(A):225-33.

8 Fritz RC, Steinbach LS, Tirman PFJ, et al. MR imaging of the elbow. An update. Radiol Clin North Am 1997;35(1):117-44.

\section{Right upper lobe consolidation: an unusual complication of an uneventful endotracheal intubation}

\section{Sunderamoorthy, S Ahuja, A Grant, T Mian}

A 28 year old fit and healthy Caucasian man had a Bankart's repair of the left shoulder under general anaesthetic for a recurrent dislocation of the shoulder. The operative procedure was uneventful. Following extubation he was tachycardic and saturation dropped in the recovery room. The chest radiograph revealed shadowing in the right lung and he was diagnosed to have right middle lobe collapse. Subsequently the radiograph was reported as right upper lobe consolidation by the radiologist. We wish to report this unusual complication and the difficulty in diagnosis of such a complication occurring following an uneventful anaesthetic.

C uffed endotracheal tubes are used for airway management in the operating room, emergency room, and aware that right main stem intubation may precipitate leftsided pulmonary atelectasis. ${ }^{1}$ Inadvertent right main bronchus intubation can also cause paradoxical collapse of a portion of the right upper lobe. ${ }^{2}$ There had been reports of right upper lobe collapse occurring after an uneventful endotracheal intubation. ${ }^{3}$ There had also been reports of right middle lobe collapse occurring, in isolation or in combination with a right upper lobe collapse, after an uneventful endotracheal intubation. Right upper lobe consolidation as a complication of endotracheal intubation has not been reported. We wish to report such a complication occurring in a young man who had an uneventful endotracheal intubation where he was thought to have had a right middle collapse and subsequently reported to have right upper lobe consolidation. The radiological features of right middle lobe collapse and right upper lobe consolidation and ways to diagnose them are discussed.

\section{CASE REPORT}

A 28 year old Caucasian underwent a Bankart's repair of the left shoulder under general anaesthetic for a recurrent dislocation of the shoulder. He was fit and healthy nonsmoker with no premorbid medical conditions (American Society of Anaesthesiologists (ASA) Grade 1). He had an uncomplicated endotracheal intubation and his electrocardiogram (ECG), blood pressure, $\mathrm{SaO}_{2}, \mathrm{ETCO}_{2}$, and oxygen inspiration were satisfactory throughout the operative period. The operative procedure was uneventful. Following extubation he was tachycardic and $\mathrm{SaO}_{2}$ was $82 \%$ in the recovery room. Clinically there was reduced air entry over the apex and the middle of the right chest with good air entry in the lung base. He was resuscitated immediately and his $\mathrm{SaO}_{2}$ improved

Abbreviations: ASA, American Society of Anaesthesiologists; ECG, electrocardiogram 


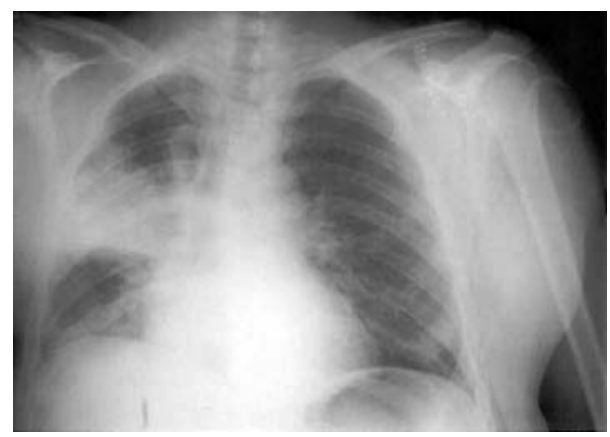

Figure 1 Anteroposterior radiograph showing right upper lobe consolidation. Reproduced with permission.

to $95 \%$ ( $60 \%$ oxygen inhalation). ECG was normal and an $x$ ray of the chest (fig l) revealed shadowing in the right lung, which was thought to be right middle lobe collapse. Postoperatively he was treated with intravenous antibiotics, humidified oxygen, and chest physiotherapy. He was discharged home after 5 days of treatment. At 2 weeks follow up he had no chest problems and a chest radiograph showed complete expansion of the lung (fig 2). The radiologist reported his chest radiographs as right upper lobe consolidation (fig 1).

\section{DISCUSSION}

Right bronchial airway obstruction is an infrequent complication of endotracheal intubation. Following emergency resuscitation procedures, it is more common than generally acknowledged. ${ }^{4}$ The upper lobe bronchus on the right side arises as an offshoot from the right main bronchus, whereas the left upper lobe bronchus arises further away from the carina as a bifurcation of the main trunk. In adults, the right main bronchus is only $2 \mathrm{cms}$ and shorter. The right upper lobe bronchus can also arise from the lower end of the trachea. Therefore, occlusion of the upper lobe opening occurs when the right lobe bronchus is inadvertently intubated. ${ }^{5}$

Complete obstruction of the left main stem bronchus produces rapid atelectasis of the lung. ${ }^{5}$ Collapse of the right upper lobe is a rarely reported form of lobar atelectasis in the intubated patient. This usually follows inadvertent intubation of the right main bronchus. Seto et al observed that main stem intubation does not cause immediate collapse of the left lung, right lung preferential ventilation does not preclude right upper lobe collapse, and right upper lobe collapse can occur very rapidly after inadvertent intubation of the right main stem bronchus. ${ }^{2}$

Numerous mechanisms have been hypothesised: anatomical considerations of the right upper lobe bronchus, Bernoulli-type mechanism, compression of the upper lobe from hyperinflation of the lower lobes, and resorption atelectasis are the various factors leading to the right upper lobe collapse following intubation. ${ }^{2}{ }^{3}$ Halpern et al had reported the aetiology as multifactorial. This complication can occur at any time following an eventful or uneventful intubation. ${ }^{3}$

In our patient, the chest radiographs taken in the recovery room showed homogenous opacity in the right middle zone and the right heart border could not be seen. A diagnosis of right middle lobe collapse was made. Seto et al had reported right middle lobe collapse, either alone or in combination with right upper lobe collapse, occurring as a complication of inadvertent right bronchus intubation. ${ }^{2}$

It was a surprise when the radiologist reported the radiographs as right upper lobe consolidation. There has been no report of patients developing acute right upper lobe

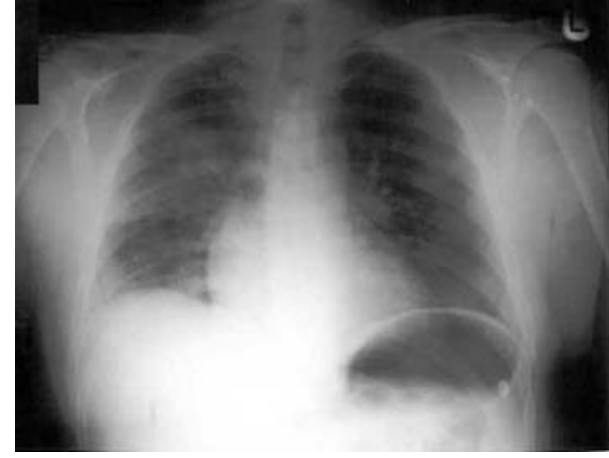

Figure 2 Radiograph showing the cleared consolidation. Reproduced with permission.

consolidation following an endotracheal intubation. In right middle lobe collapse the horizontal fissure and lower half of the oblique fissure move towards one another. In right upper lobe consolidation, the consolidation is confined by the horizontal fissure inferiorly and the upper half of the oblique fissure posteriorly. This can be best seen in the lateral projection. The signs of right middle lobe collapse are subtle in frontal projection and hence the difficulty in differentiating between right upper lobe consolidation and right middle lobe collapse.

In our patient the ventilation was uneventful throughout the operative procedure. One probable explanation was that there might have been a mucous plug obstructing the right upper lobe bronchus causing the consolidation and then clearing subsequently with treatment. Another possible reason was that the endotracheal tube might have displaced when transferring the patient from the operating table to the bed. This could lead to the endotracheal tube migrating into the right main bronchus thereby causing a collapse of the right upper lobe and then the patient subsequently developing an acute consolidation. If there is doubt in the differentiating between a collapse and a consolidation on an anteroposterior view of a chest radiograph, obtaining a lateral view would help in diagnosis for the reasons described earlier.

Anaesthetists, intensivists, and the emergency physicians need to be aware of right upper lobe consolidation occurring as complication of endotracheal intubation and the difficulty in the radiographic diagnosis of such a complication.

\section{Authors' affiliations}

D Sunderamoorthy, S Ahuja, A Grant, T Mian, Royal Gwent Hospital, Newport, UK

Competing interests: none declared

Correspondence to: Mr D Sunderamoorthy, 3 Burwell Close, Pontprennau, Cardiff, CF23 8NS, UK; dsundar6@hotmail.com

Accepted for publication 26 March 2004

\section{REFERENCES}

1 Tisi GM, Twigg HL, Moser KM. Collapse of left lung induced by artificial airway. Lancet 1968;1:791-3.

2 Seto K, Goto H, Hacker DC, et al. Right upper lobe atelectasis after inadvertent right main bronchial intubation. Anaesth Analg 1983;62:851-4.

3 Halpern NA, Siegel RE, Papadakos PJ, et al. Right upper lobe collapse following uneventful endotracheal intubation. J Card Anaes 1989;3(5):620-4.

4 Twigg HL, Buckley CE. Complications of endotracheal intubation. 1970;3:452-4.

5 Baraka A, Jaude CA, Baroody MA, et al. Right upper lobe collapse following right bronchial intubation. ME J Aesth 1985;8(3):255-8. 


\section{Traumatic atlantoaxial rotatory subluxation}

\section{T B Crook, C A Eynon}

Emerg Med J 2005;22:671-672. doi: 10.1136/emj.2003.013045

\begin{abstract}
Atlantoaxial rotatory subluxation should be considered in the presentation of traumatic torticollis. This case report discusses the characteristic radiographic findings and appropriate management.
\end{abstract}

$\mathrm{T}$ orticollis is a relatively frequent presenting sign to an emergency department. It describes lateral flexion of the neck and contralateral rotation, with a variable degree of flexion. The causes may be divided into traumatic and nontraumatic. The differential diagnosis of non-traumatic torticollis should include, particularly in children, congenital cervical spine anomalies, head and neck infection (for example, otitis media, pharyngitis, or retropharyngeal abscess), and tumours in the posterior fossa or upper cervical spine. ${ }^{1}$ Other causes include drug-induced torticollis-for example, with phenothiazines-and the movement disorder spasmodic torticollis. Traumatic causes of torticollis include atlantoaxial rotatory subluxation, atlantoaxial dislocation, cervical vertebral fractures, and injury to the cervical musculature.

This article highlights a case of atlantoaxial rotatory subluxation with the aim of improving awareness of this condition to enable early recognition. Appropriate management options and outcomes are discussed.

\section{CASE HISTORY}

A 15 year old girl tackled an opponent while playing rugby. During the tackle her head was forcibly extended and rotated to the right. She attended her local emergency department complaining of neck pain with her neck in fixed rotation to the right. She had no neurological sequelae. Plain $x$ rays showed abnormality at the atlantoaxial joint (fig 1). A computed tomography (CT) scan confirmed a $45^{\circ}$ rotatory subluxation of $\mathrm{C} 1$ on $\mathrm{C} 2$, with forward subluxation of the lateral mass of the atlas off the axis on the left and posterior subluxation on the right (fig. 2). The atlantodental interval was not increased and no fracture was identified. The patient was transferred to the regional neurosurgical centre. Management consisted of analgesia, sedation, and application of halo skull traction. This allowed clinical reduction of the subluxation within one hour of application. Reduction was confirmed by CT scan. The patient remained in traction for six days before being mobilised in a rigid neck collar. She was discharged without further problems after 11 days. The rigid collar was removed after eight weeks. Outpatient review at three months revealed a full range of painless neck movement.

\section{DISCUSSION}

The atlantoaxial joint primarily facilitates rotation and is stabilised in the anteroposterior plane by the transverse ligament and joint capsule. The alar ligaments, which pass from the lateral occipital processes to the posterolateral margin of the odontoid apex, prevent anterior shift of the atlas on the axis but mainly function in preventing excessive rotation at the atlantoaxial joint. There is evidence from magnetic resonance imaging to suggest that alar ligament disruption is the mechanism by which rotatory subluxation occurs. $^{23}$ The lateral mass of the atlas rotating posteriorly

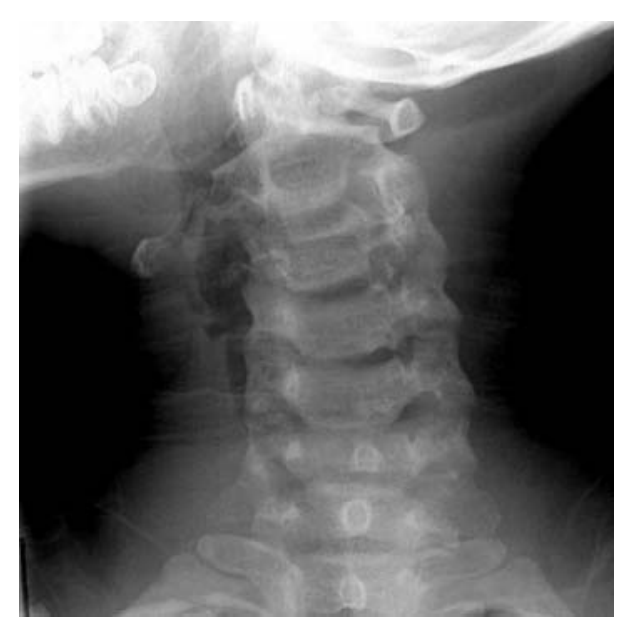

Figure 1 Plain anteroposterior $x$ ray of cervical spine demonstrating torticollis with chin directed to the right.

locks behind the ipsilateral lateral mass. Conditions with associated ligamentous laxity or congenital atlantoaxial abnormalities therefore carry an increased incidence of rotatory subluxation. These include Down's syndrome, Morquio's syndrome, Marfan's syndrome, and rheumatoid arthritis. Grisel's syndrome describes non-traumatic subluxation of the atlantoaxial joint from inflammatory ligamentous laxity following an infectious process. ${ }^{4}$

Traumatic atlantoaxial rotatory subluxation is predominantly a paediatric phenomenon, with rare occurrence in adults. ${ }^{5}$ It should be included in the differential diagnosis of patients presenting with torticollis following even minor trauma. Two classification systems for rotatory subluxation

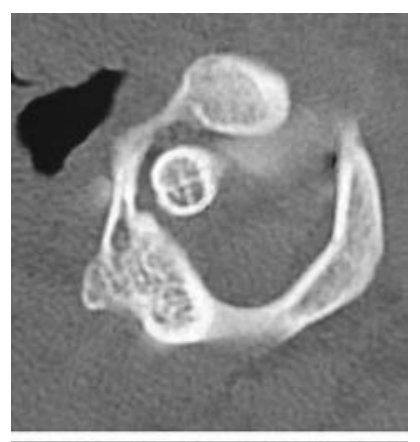

Figure 2 Computed tomography scan of cervical spine showing approximately $45^{\circ}$ rotation of the skull and $\mathrm{Cl}$ to the right in relation to C2. Approximately three quarters of the $\mathrm{C} 2$ facet is exposed.

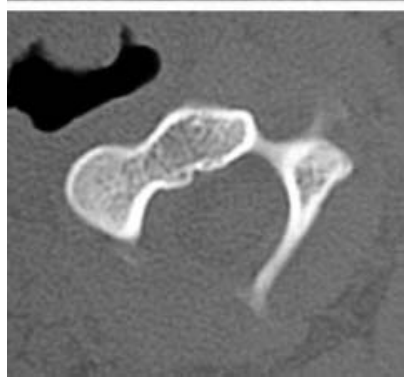


have been described: the Fielding and Hawkins system, ${ }^{7}$ and that of White and Panjabi. ${ }^{8}$ These are based on radiological findings, describing the direction of atlantal displacement and the pivotal axis.

Radiographic features of rotatory subluxation are of persistent asymmetry of the odontoid peg in relation to the lateral masses of the atlas, uncorrected by head rotation. Plain $x$ rays of the cervical spine will detect approximately $93 \%$ of rotatory subluxations compared with a detection rate of $54 \%$ with CT. When combined, a sensitivity of $99 \%$ has been described. ${ }^{9}$ Complex motion tomographic studies or dynamic CT have also been recommended for the diagnosis of rotatory subluxation. ${ }^{69}$

Acute traumatic atlantoaxial rotatory subluxation is often reduced easily. ${ }^{2610}$ The length of time between injury and reduction appears to correlate with rates of recurrence and failure of reduction by non-surgical techniques. ${ }^{10}$ Evidence supports the use of early cranial traction in conjunction with benzodiazepines. ${ }^{6}{ }^{10}$ This is followed by external immobilisation (Philadelphia collar or Guilford orthosis) for six weeks. The patients achieve good long term stability. ${ }^{6}{ }^{10}$ In cases of recurrence, further cranial traction followed by external immobilisation (once reduced) for three months is advocated.$^{10}$ For recurrent or irreducible subluxation, open reduction and posterior atlantoaxial fusion may be required. ${ }^{6}{ }^{710}$

\section{Authors' affiliations}

T B Crook, Department of Neurosurgery, Wessex Neurological Centre, Southampton, UK
C A Eynon, Neurosciences Intensive Care Unit, Wessex Neurological Centre, Southampton, UK

Competing interests: none declared

Correspondence to: Dr C A Eynon, Director of Neurosciences Intensive Care, Wessex Neurological Centre, Tremona Road, Southampton SO16 6YD, UK; Andy.Eynon@suht.swest.nhs.uk

Accepted for publication 30 January 2004

\section{REFERENCES}

1 Muniz AE, Belfer RA. Atlantoaxial rotary subluxation in children. Pediatr Emerg Care 1999;15:25-9.

2 Niibayashi H. Atlantoaxial rotatory subluxation. A case report. Spine 1998;23:1494-6.

3 Willauschus WG, Kladny B, Beyer WF, et al. Lesions of the alar ligaments. In vivo and in vitro studies with magnetic resonance imaging. Spine 1995;20:2493-98.

4 Mathern GW, Batzdorf U. Grisel's syndrome. Cervical spine clinical, pathologic, and neurologic manifestations. Clin Orthop 1989;244:131-46.

5 El-Khoury GY, Clark CR, Gravett AW. Acute traumatic rotatory atlanto-axial dislocation in children. A report of three cases. J Bone Joint Surg Am 1984;66:774-7.

6 Phillips WA, Hensinger RN. The management of rotatory atlanto-axial subluxation in children. J Bone Joint Surg Am 1989:71:664-8.

7 Fielding JW, Hawkins RJ. Atlanto-axial rotatory fixation (fixed rotatory subluxation of the atlanto-axial joint). J Bone Joint Surg Am 1977;59:37-44.

8 White AA III, Panjabi MM. Clinical biomechanics of the spine. Philadelphia: JB Lippincott, 1978:125-9.

9 Woodring JH, Lee C. The role and limitations of computed tomographic scanning in the evaluation of cervical trauma. J Trauma 1992;33:698-708.

10 Subach BR, McLaughlin R, Albright AL, et al. Current management of paediatric atlantoaxial rotatory subluxation. Spine 1998;23:2174-9.

\section{Primary intraventricular haemorrhage in an 11 year old child}

\section{B S Rayen, F M Russell}

A n 11 year old boy walked into our accident and emergency department with his mother having woken up with headache four hours ago. He was known to have mild learning difficulties for speech and language, but was otherwise previously fit and healthy. He was not on any medications, and he did not have any history of trauma. He had vomited twice at home. On initial examination, he did not have a high temperature, rash, or meningeal symptoms, and his Glasgow Coma Scale score was E4 M6 V5. He had no neurological signs or papilloedema and the pupils were normal. He had no neck stiffness or meningeal signs. His pulse rate was 60 per minute and a subsequent electrocardiogram showed sinus bradycardia. His blood pressure was normal.

During further examination his conscious level deteriorated. He became vague and disinterested, and then he began babbling. He had a fluctuating conscious level, at best occasional spontaneous eye opening, localising to pain with inappropriate words. His respiratory rate was normal and he was maintaining his airway. At this point, the most likely clinical diagnosis was acute encephalitis and he was treated with intravenous cefotaxime and aciclovir. Investigations including full blood count, urea and electrolytes, C-reactive protein, glucose, liver function tests, and clotting profiles were normal. An urgent computed tomography (CT) scan of brain revealed recent haemorrhage in predominantly the right lateral, third, and fourth ventricles (fig 1). There was no evidence of acute hydrocephalus. Following our initial management he was transferred to the neurosurgical unit for continuing care. He then developed mild weakness of his left limbs. He underwent further CT scanning of brain and was treated conservatively. The CT scan and a cerebral angiogram performed at a later date did not reveal any underlying cause, such as an arteriovenous malformation or aneurysm.

Four months later the mild left sided weakness persists and it was planned to carry out magnetic resonance imaging (MRI) after six months of the haemorrhage to exclude an angiographically occult lesion such as cavernoma. The MRI confirmed the findings of the CT scan performed previously.

Spontaneous intracranial haemorrhage is rare in adolescence. Primary intraventricular haemorrhage is an uncommon subgroup. Little is known about the clinical and imaging features of primary intraventricular haemorrhage. Livingston et al reported that the clinical features in this condition were not specific, but that altered consciousness, headache, vomiting, and focal signs were common. ${ }^{1}$ Vascular malformations may result in intraventricular haemorrhage in children. Such presentation accounts for 3\% of adult 


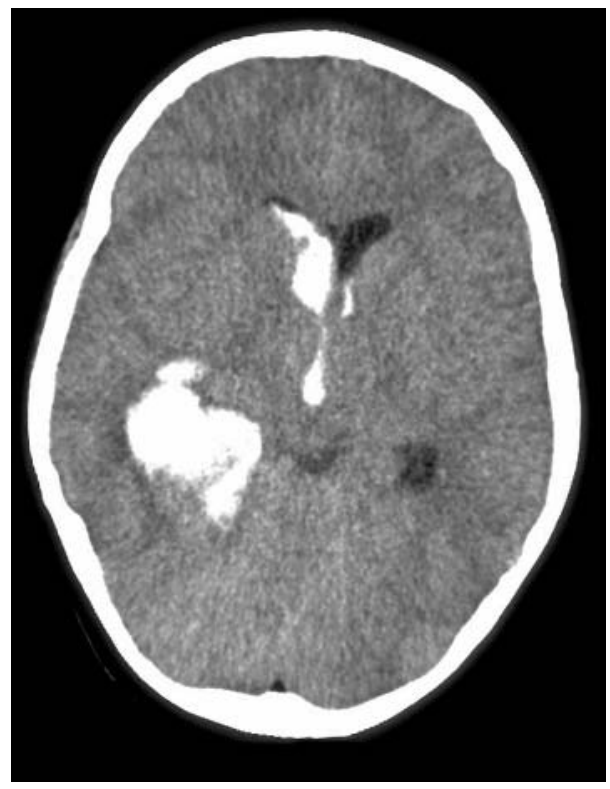

Figure 1 Computed tomography scan of an 11 year old boy presenting with spontaneous intracranial haemorrhage.

intracranial bleeds but relevant data about this association have not been reported in children. ${ }^{2}$ Certain prognostic factors like initial level of consciousness, ${ }^{3}$ early hydrocephalus, ${ }^{4}$ and delay in diagnosing intracranial aneurysms ${ }^{5}$ may adversely affect the outcome with severe neurological deficits and high mortality. In our case an early cranial CT scan ensured urgent neurosurgical referral. The absence of the abovementioned adverse prognostic factors might explain the reasonable outcome in our patient with little in the way of neurological deficit. Therefore to diagnose this serious condition, a high degree of clinical suspicion and a low threshold for early use of CT is essential, particularly in children who have difficulties with expression and speech.

\section{Authors' affiliations \\ B S Rayen, F M Russell, Royal Hospital for Sick Children, Yorkhill, Scotland \\ Competing interests: none declared}

Correspondence to: B S Rayen, Royal Hospital for Sick Children, Yorkhill, Scotland; drrayen@yahoo.com

Accepted for publication 2 February 2004

\section{REFERENCES}

1 Livingston JH, Brown JK. Intracranial haemorrhage after the neonatal period. Arch Dis Child 1986;61:538-44.

2 Parmar RC, Bavdekar SB, Goel A, et al. Primary intraventricular haemorrhage: a rare presenting feature of arteriovenous malformation in children. J Indian Med Assoc 2002;100:254-6.

3 Nilsson OG, Lindgren A, Brandt L, et al. Prediction of death in patients with intracerebral hemorrhage: a prospective study of a defined population. J Neurosurg 2002;97:531-6.

4 Passero S, Ulivelli $M$, Reale F. Primary intraventricular haemorrhage in adults. Acta Neurol Scand 2002;105:115-19.

5 Vannmreddy P, Nanda A, Kelley R, et al. Delayed diagnosis of intracranial aneurysms: confounding factors in clinical presentation and the influence of misdiagnosis on outcome. South Med J 2001;94:1108-11.

\section{An unusual presentation of baclofen overdose}

\section{C-F Chong, T-L Wang}

Emerg Med J 2005;22:673-674. doi: 10.1136/emj.2003.011908

Baclofen has become increasingly popular in the treatment of spasticity disorders. Its availability for misuse has also increased. We report a case of baclofen overdose in a 20year-old man, who manifested atypical symptoms of baclofen overdose-that is, delirium and rhabdomyolysis. He was treated successfully with full supportive management, and was discharged from the hospital on the 12th day following admission. If a past medication history is not immediately available, baclofen overdose should be included in the differential diagnosis of an acutely confused patient complicated with rhabdomyolysis, as routine toxicology screening does not include baclofen.

B aclofen is commonly used to treat spasticity. Reported adverse effects of its overdose include somnolence, coma, seizures, respiratory depression, and cardiac conduction abnormalities. We describe a patient with baclofen overdose presenting to the emergency department (ED) with atypical symptoms of acute delirium and rhabdomyolysis.

\section{CASE REPORT}

A 20-year-old man was found lying unconscious on the floor in his apartment and was brought to the emergency department by ambulance. Initially, no past medical history could be obtained. Physical examination at admission showed a young man with obvious disorientation (Glasgow coma scale score 13). Vital signs were: temperature $37.4^{\circ} \mathrm{C}$, blood pressure 120/70 $\mathrm{mmHg}$, pulse 92 beats/min, and respiratory rate 24 breaths/min. Pupils were $2.5 \mathrm{~mm}$ diameter bilaterally, with prompt reaction to light. External ocular movements were full and free. Nuchal rigidity or carotid bruits were not detected. Findings on examination of the heart, lungs, vascular system, and abdomen were unremarkable. Neurological examination revealed full strength of both upper and lower limbs equally. Knee jerks were normal, but ankle jerks were decreased bilaterally. Plantar responses were bilaterally downward (Babinkski's sign). Light touch and pinprick sensation, cranial nerve examination, and cerebellar examination could not be performed because of the patient's restlessness. Laboratory tests revealed normal haemoglobin and platelet counts but the

Abbreviation: CPK, creatinine phosphokinase 
white blood cell count was elevated at $15.6 \times 10^{3}$ cells $/ \mathrm{mm}^{3}$. Glucose, blood urea nitrogen, creatinine, sodium, potassium, and ionised calcium were within normal limits. Initial creatinine phosphokinase (CPK) level was greater than $10 \times 10^{3} \mathrm{IU} / \mathrm{L}$ (normal range 24-204), and test for urine myoglobin was positive. Urine drug screen was negative for narcotics, cocaine, and amphetamines. ECG showed sinus tachycardia. Computed tomography of the head and cerebrospinal fluid studies were negative.

The patient was admitted to the intensive care unit with an initial diagnosis of meningoencephalitis and rhabdomyolysis. In addition to supportive management, he also received vigorous hydration, alkaline diuresis, and empirical antibiotics for coverage of probable meningitis. Renal function remained normal and CPK rapidly fell to within normal limits 2 days after admission. He was transferred to the medical ward on day 3 and was able to recall that he had ingested 30 pills of baclofen (Befon; $5 \mathrm{mg} / \mathrm{tablet}$ ) in a suicide attempt about 36 hours before his arrival to the ED. He admitted that he irregularly took baclofen (5-10 mg a day) for treatment of spasticities due to amyotrophic lateral sclerosis. Co-ingestion of other drugs or alcohol was denied. The patient also had pains, swelling, and some pressure sores in his left buttock and thigh. An electroencephalogram performed 7 days after admission revealed diffuse cortical dysfunction compatible with encephalopathy. Other studies performed included somatosensory evoked potentials and magnetic resonance imaging of the brain, which were normal. He was discharged in excellent neurological function on day 12.

\section{DISCUSSION}

Baclofen, a lipophilic analogue of the naturally occurring neurotransmitter gamma-aminobutyric acid (GABA), is the drug of choice for treatment of spasticity from spinal cord lesions and multiple sclerosis. It appears to act as an agonist at bicuculline insensitive GABA receptors in the spinal cord to decrease neurotransmitter release from presynaptic terminals. ${ }^{1}$

After a single therapeutic dose, baclofen is rapidly absorbed from the gastrointestinal tract. Blood levels peak within 2 hours. The serum half-life is 2-6 hours, which can be significantly prolonged after an overdose. The majority of this drug is excreted unchanged in the urine. ${ }^{2}$ Signs of toxicity have been reported after ingestion of as little as $100 \mathrm{mg}$ of baclofen. ${ }^{3}$ Adverse effects of baclofen overdose are well defined in the literature, and include somnolence, coma, seizures, encephalopathy, respiratory depression, flaccidity, hyporeflexia, and cardiac conduction abnormalities. ${ }^{4}$ None of the patients described previously in the literature presented with rhabdomyolysis and acute delirium as in our case. Although uncommon, agitated confusion can be a pattern of baclofen encephalopathy. The mechanism for rhabdomyolysis in this case is uncertain. Drugs impairing the central nervous system, including baclofen, can cause rhabdomyolysis by pressure induced ischaemia due to prolonged immobilisation and muscle compression. This is supported in our case by the presence of pressure sores on the patient's left gluteus and thigh. Unwitnessed seizures may also have contributed to muscle breakdown in this case.

In conclusion, in the absence of detailed past medication history, an acutely confused patient complicated with rhabdomyolysis should have baclofen overdose included in the differential diagnosis, as routine toxicology screening does not include baclofen. Such atypical signs should be recognised early, as drug discontinuation and full supportive treatment result in good outcome, provided no hypoxic or ischaemic insult has occurred before medical attention.

\section{Authors' affiliations \\ C-F Chong, T-L Wang, Emergency Department, Shin-Kong Wu Ho-Su Memorial Hospital, Taipei, Taiwan, Republic of China \\ Competing interests: none declared}

Correspondence to: Dr C-F Chong, Emergency Department, Shin-Kong Wu Ho-Su Memorial Hospital, No.95 Wen-Chang Rd, Shih-Lin District, Taipei City 111, Taiwan, Republic of China; jackchong@tmu.edu.tw

Accepted for publication 25 November 2004

\section{REFERENCES}

1 Ghose K, Holmes KM, Matthewson K. Complications of baclofen overdosage. Postgrad Med J 1980;56:865-7.

2 Gerkin R, Curry SC, Vance MV, et al. First-order elimination kinetics following baclofen overdose. Ann Emerg Med 1986; 15:843-6.

3 Lee TH, Chen SS, Su SL, et al. Baclofen intoxication: report of four cases and review of the literature. Clin Neuropharmacol 1992;15:56-62.

4 Perry HE, Wright RO, Shannon MW, et al. Baclofen overdose: drug experimentation in a group of adolescents. Pediatrics 1998;101:1045-8.

\section{An unusual swelling in the neck}

\section{A A Abbasi, N S Harrop}

Venous thrombosis is a fundamental pathological entity. Our patient provides an opportunity to consider etiology in terms of Virchow's classic triad. We also draw attention to the effort syndrome, in which recurrent, vigorous exertion of an upper extremity is thought to produce venous thrombosis by virtue of local endothelial trauma.

\section{CASE HISTORY}

A 44 year old man was referred by his General Practitioner to the A\&E department with a 4 to 5 day history of left-sided neck swelling, symptoms of pleuritic chest pain, and weight loss of one stone.

He had just returned from holiday in Africa and had suffered from altitude sickness whilst climbing Mount 


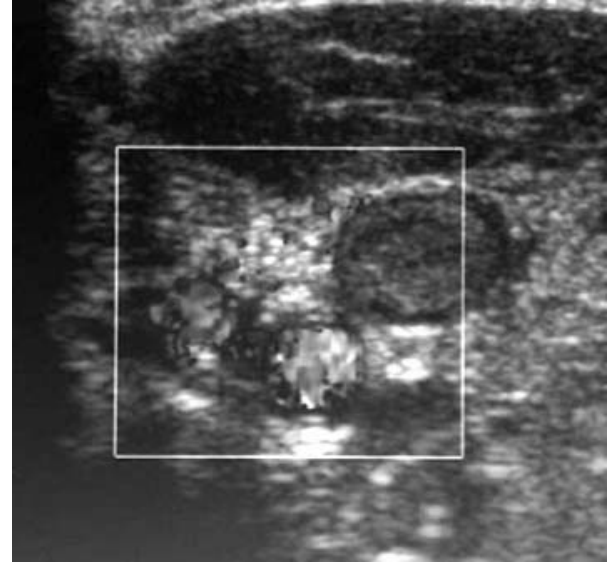

Figure 1 Showing an extensive thrombus within the left juglar vein, which extends to brachiocephalic and left axillary veins.

Kilimanjaro. He had then suffered a prolonged bout of diarrhoea.

At a first visit, the GP had advised fluids because of dehydration. After a few days, the patient developed swelling in the left supraclavicular region with intermittent chest pain. He was, therefore, referred to A\&E.

On examination he looked well. There was a non-pulsatile, diffuse swelling, in the left supraclavicular region. It extended to the base of the neck. Its margins were not palpable. The swelling was red, hot, and tender. There was no lymphadenopathy.

The chest was clear and the heart sounds were pure. Abdominal examination was unremarkable.

He was thought to have an abscess. However, chest $\mathrm{x}$ rays showed broadening of the left superior mediastinum with a small left basal effusion. Ultrasound of the neck demonstrated extensive thrombus in the left jugular, subclavian, and axillary veins (figure 1). A thoracic CT scan demonstrated diffuse tissue swelling in the left side of the neck and superior mediastinum. CT did not disclose any lymphadenopathy. There were bilateral pleural effusions, more so on the left (figure 2).

The patient was admitted to a medical ward and he was treated for venous thrombosis with low molecular weight heparin initially, then Warfarin. The swelling improved. His CRP, initially significantly elevated (200), returned to normal. His full blood count, renal functions and liver functions were normal

The patient was discharged after 5 days of hospital admission with advice to continue Warfarin for 6 months. He will have another CT scan after 6 weeks.

\section{COMMENT}

Spontaneous thrombosis of the axillary or subclavian veins was first postulated as a cause of upper extremity pain and swelling by Sir James Padget in 1875. ${ }^{1}$ Von Schroetter demonstrated thrombotic occlusion of upper limb veins, hence the Padget-Schroetter syndrome. More recently, the association between strenuous repetitive movement of the upper extremity and axillosubclavian thrombosis has been recognised and termed effort syndrome. ${ }^{2}$ Apart from iatrogenic

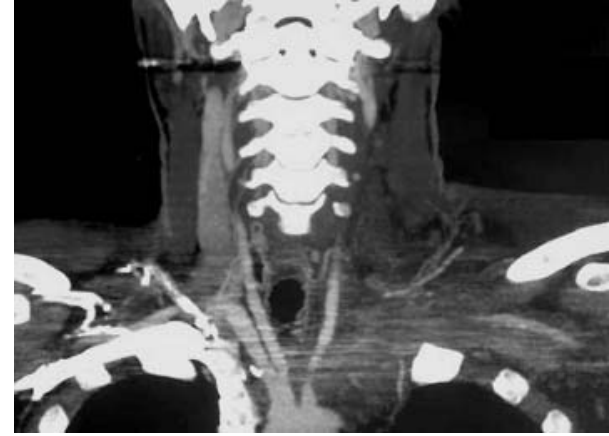

Figure 2 Showing an extensive thrombus within the left juglar vein, which extends to brachiocephalic and left axillary veins.

factors such as catheter placement, venous thrombosis of the axillary, or subclavian vein may be caused by external compression by an anatomical structure such as a congenital cervical rib or by the pathological development of a local tumour. ${ }^{3}$

Virchow's triad explains thrombosis in terms of venous stasis, vessel wall abnormality or disorders of the blood itself. ${ }^{4}$

In this patient, it is suspected that venous stasis may have been added to local tissue trauma. The patient had worn a rucksack, possibly obstructing venous flow as well as causing trauma to the vessel wall. He had suffered altitude sickness and it is of interest that hypoxia may also produce endothelial injury. ${ }^{5}$ Finally, he had suffered a period of significant dehydration likely to have been attended by hemoconcentration and increased blood viscosity. In other patients, it is important to bear in mind that the occurrence of thrombosis at an unusual anatomic location may provide the first evidence of a hypercoagulable state, especially if there is a previous personal or a positive family history of thrombosis. ${ }^{6}$ Suitable investigations would then include a haemobilia screen.

\section{Authors' affiliations}

A A Abbasi, SpR in Accident and Emergency Medicine, Blackpool Victoria Hospital, Blackpool, Lancashire, UK

N S Harrop, Consultant in Accident and Emergency Medicine, Blackpool Victoria Hospital, Blackpool, Lancashire, UK

Correspondence to: A A Abbasi, Accident \& Emergency Department, Blackpool Victoria Hospital, Blackpool, FY3 8NT;

aaabbasi38@hotmail.com

Accepted for publication 26 February 2004

\section{REFERENCES}

1 Coon WW, Willis PW. Thrombosis of axillary and subclavian veins. Arch Surg 1967;94:657-63.

2 Adams JT, DeWeese JA. Effort thrombosis of axillary and subclavian veins. Trauma 1971;11:923-30

3 Horattas MC, Wright DJ, Fenton $\mathrm{AH}$. Changing concepts of deep vein thrombosis of the upper extremity-report of a series and review of the literature. Surgery 1988;104:561-7.

4 Paget J. Clinical lectures and essays. Green London, UK: Longman, 1875.

5 Cromwell DL. Effort thrombosis of the subclavian and axillary veins: review of the literature. Ann Intern Medicine 1960;52:1337-43.

6 Thomas DP, Roberts HR. Hypercoagulability in venous and arterial thrombosis. Ann Intern Med 1997; 126:638-44. 


\section{Butane encephalopathy}

\section{Harris, Z Mirza}

Volatile solvent abuse (VSA) is defined at the "intentional inhalation of a volatile substance for the purpose of achieving a euphoric state". The lifetime prevalence of VSA in the UK remains steady at around $15 \%$, the fourth highest rate in Europe, and VSA is the most common form of drug abuse in the 11-15 year age group in England and Wales. A 13 year old girl presented to the accident and emergency unit following inhalation of butane based deodorant, which resulted in a prolonged semiconscious state with encephalopathic symptoms.

$\mathrm{V}$ olatile solvent abuse (VSA) is defined at the "intentional inhalation of a volatile substance for the purpose of achieving a euphoric state ${ }^{\prime \prime}{ }^{1}$ The lifetime prevalence of VSA in the UK remains steady at around 15\%, the fourth highest rate in Europe, ${ }^{2}$ a figure aided by the ready availability of these products. We present the case of a 13 year old girl who presented to the accident and emergency (A\&E) unit following inhalation of a large quantity of butane based deodorant, which resulted in a prolonged semiconscious state with encephalopathic symptoms.

\section{CASE REPORT}

The patient, who was markedly obese (body mass index $>30$ ) was brought by ambulance to A\&E, having been found unconscious on her bedroom floor by her mother. On arrival, the patient was agitated and combative with a patent airway, tachycardia ( 131 beats/min), and tachypnoea ( 28 beats/min). She was normotensive with a low grade pyrexia $\left(37.6{ }^{\circ} \mathrm{C}\right.$ tympanic). Her Glasgow Coma Score (GCS) level was 10/15 (E2/4, M5/6, V3/5).

Arterial blood gas analysis, performed on a sample taken from the patient's right radial artery, showed respiratory acidosis $\left(\mathrm{pH} 7.35, \mathrm{PO}_{2} 10.4 \mathrm{kPa}, \mathrm{PCO}_{2} 7.2 \mathrm{kPa}\right.$ on 5 litres oxygen/minute via face mask). Venous blood tests (full blood count, clotting screen, urea and electrolytes, liver function tests, bone profile, paracetamol and salicylate levels, random glucose, $\mathrm{C}$ reactive protein, and amylase) were within normal limits. Further examination found four superficial "deliberate self harm" scars on her forearms. Her mother reported that she had recently been the victim of bullying at school and that the third anniversary of her father's death was approaching. The paramedic crew had found two new, but empty cans of a commercial deodorant at her bedside, the principle inactive components of which are butane and hydrofluorocarbon 152A, which act as propellants. An electrocardiogram showed sinus tachycardia, and chest $x$ ray showed no abnormalities.

After consultation with the paediatric consultant on call, prophylactic broad spectrum intravenous antibiotics and antivirals were commenced, assuming a possible infective cause for her symptoms. Prophylactic corticosteroids were not given.

The patient remained stable 18 hours post-admission, but with a GCS of 10/15 (E2/4, M5/6, V3/5). Lumbar puncture was performed and cerebrospinal fluid (CSF) analysis showed no organisms, normal glucose, and slightly elevated protein. Blood, urine, and sputum samples were sent for microscopy, culture, and sensitivity, and a urine sample was sent for "drugs of abuse" screening (amphetamines, opiates, barbiturates, benzodiazepines, cannabinoids, and cocaine), all of which were found to be negative.

By 24 hours post-admission, the patient was alert but experiencing episodes of drowsiness and disorientation. She also had a marked nystagmus, and on day 3, when she was first able to stand, she was ataxic with slurred speech. Magnetic resonance imaging of her brain performed 4 days after admission was unremarkable. Electroencephalogram performed the same day found abnormal delta and theta waveforms, consistent with a drug induced encephalopathy.

While in hospital, the patient was fully assessed by the paediatric psychiatry team, during which she admitted regular solvent misuse. It appeared that the various recent traumatic events in her life had provoked a significant increase in the amount of solvent used. She denied using any other recreational drugs or alcohol.

She was discharged 14 days after first presenting, the length of admission partly explained by her complicated social and psychological problems. To facilitate the administration of her antibiotics for a further week, a peripheral long line was placed in her distal right saphenous vein. All CSF, blood, sputum, and urine samples sent for microbiology had shown no abnormalities or growth.

In view of her investigation results and her admission to butane use, a diagnosis of butane induced encephalopathy was made, one similar case having being reported previously in the medical literature. ${ }^{3}$ Despite the elimination half life of butane being around 10 minutes, the prolonged duration of her symptoms could well be explained by her obesity, the large quantity of butane inhaled, and the extreme lipophilic nature of the misused solvent. ${ }^{4}$ The decision to continue antibiotic treatment was made on the basis that as little was known by the clinical teams about solvent use and its effects, thus as an additional safety measure the normal infection protocols should be adhered to despite all investigations showing no infective process.

\section{DISCUSSION}

Butane is a low molecular weight aliphatic hydrocarbon and the principle propellant used in spray on deodorant since the elimination of chlorofluorocarbons. It is also the most commonly misused volatile solvent in the UK, and was the cause of $52 \%$ of the 64 known solvent related deaths in $2000 .^{5}$ Of great concern is that $43 \%$ of these deaths occurred in young healthy subjects who were trying VSA for the first time. The majority of people who misuse solvents are aged between 12 and 17 years, with a peak around 15 years, although there are recorded cases of use among children as young as 7 years.

While there are multiple case reports of cardiac and trauma related deaths from VSA in Europe and the USA, ${ }^{7-9}$ neurological complications are less common, with only one

Abbreviations: A\&E, accident and emergency; CSF, cerebrospinal fluid; GCS, Glasgow Coma Score; VSA, volatile solvent abuse 


\begin{tabular}{l} 
Table 1 Clinical effects of butane inhalation \\
\hline CNS depression / acute confusional state \\
Cardiac arrhythmias \\
Nausea and vomiting \\
Dizziness \\
Headache \\
Abdominal pain \\
Ataxia \\
Muscle weakness \\
Photophobia \\
Hallucinations \\
Diplopia \\
Insomnia \\
Depression \\
Fatigue \\
\hline Collated from reference 3, 4, 7-11, and 13. \\
\hline
\end{tabular}

previous report of butane associated acute encephalopathy, ${ }^{3}$ one of chronic cerebral atrophy (neurodevasation), ${ }^{10}$ and one of prolonged hemiparesis. ${ }^{15}$

Cardiac arrhythmias and vagal stimulation leading to cardiac arrest, along with anoxia, oedema, and respiratory depression $^{11}$ are the principal causes of death. By spraying butane directly into the throat, the jet of fluid can cool rapidly to $-20^{\circ} \mathrm{C}$ by expansion, causing prolonged laryngospasm. ${ }^{13}$ "Sudden sniffing death syndrome", first described by Bass in $1970,{ }^{12}$ is the commonest single cause of solvent related death, resulting in 55\% of known fatal cases. ${ }^{13}$ The myocardium is hypersensitised to epinephrine by the inhaled hydrocarbon, so that any sudden stimulation or excitation of the user can result in arrhythmias brought on by intrinsic epinephrine release. This also explains the poor outcome of attempted resuscitations during which more epinephrine is routinely administered. Edwards and Wenstone ${ }^{14}$ suggest the use of amiodarone over epinephrine in cardiac arrest where VSA is suspected.

The protean presentation of VSA in A\&E (table 1) and the lack of awareness among clinical staff mean the true underlying cause of presentation is often not realised. Very few people who present will have any obvious aroma of solvent about them or a perioral "huffer's rash". Greater awareness of VSA may aid in the management of young people who present to A\&E with unusual symptom patterns. Knowledge of the contraindication of epinephrine for cardiac arrest in VSA, earlier definitive airway control and the need to nurse patients in softly lit and quiet areas, where excitation and stimulation are less likely, will improve the often poor outcome in resuscitation following VSA.

The enormous number of household products open to misuse and the exclusion of VSA in most drug awareness programmes mean that eradication of solvent misuse is unlikely. Legislation such as The Intoxicating Substance Supply Act of 1985 and The Cigarette Lighter Refill Regulation Act of 1999 are difficult to enforce, with only 53 convictions since their introduction.

The high prevalence and varied clinical presentation of volatile solvent misuse will continue to present a challenge to emergency physicians until the technical problems of developing a non-toxic solvent can be overcome.

\section{Authors' affiliations}

D Harris, Z Mirza, Department of A\&E Medicine, West Middlesex Hospital, UK

Competing interests: none declared

Correspondence to: Dr D Harris, Department of A\&E Medicine, West Middlesex Hospital, Twickenham Road, Isleworth, Middlesex, TW7 6AF, UK; drdanharris@msn.com

Accepted for publication 8 March 2004

\section{REFERENCES}

1 American Academy of Pediatrics, Committee on Substance Abuse and Committee on Native American Child Health. Inhalant abuse. Pediatrics 1996;97:420-3.

2 Society for the Prevention of Solvent and Volatile Substance Abuse (eds). European school survey project on alcohol and other drugs 2000, www.re-solv.org.

3 Doring G, Baumeister FA, Peters J, et al. Butane associated encephalopathy. Klinische Padiatrie 2002;214:295-8.

4 Nishi K, Ito N, Mizumoto J et al. Death associated with butane inhalation. Jpn J Leg Med 1985;39:214-16.

5 Field-Smith M, Bland JM, Taylor JC, et al. Trends in deaths associated with abuse of volatile substances 1971-2000, Report no.15, Department of Public Health Sciences. London: St George's Medical School, www.sghms.ac.uk/ depts/phs/vsamenu.htm.

6 Neumark YD, Delva J, Anthony JC, et al. The epidemiology of adolescent inhalant drug involvement. Arch Pediatr Adolesc Med, 1998;152:781-6.

7 Williams D. Ventricular fibrillation following butane gas inhalation. Resuscitation 1998;37:43-5.

8 Rohrig T. Sudden death due to butane inhalation. Am J Forensic Med Pathol 1997; 18:299-302.

9 Roberts MJ, Mclvor RA, Adgey AA. Aystole following butane inhalation. Br J Hosp Med 1990;44:294.

10 Bauman JE, Krenselok EP. Myocardial infarction and neurodevasation following butane inhalation. Vet Hum Toxicol 1991;33:389.

11 Flanagan R, Ruprah M, Meredith TJ, et al. An introduction to the clinical toxicology of volatile substances. Drug Safe 1990;5:359-83.

12 Bass M. Sudden sniffing death. JAMA 1970;212:2075-9.

13 Ramsey J, Anderson HR, Bloor K, et al. An introduction to the practice, prevalence and chemical toxicology of volatile substance abuse. Hum Toxicol 1989;8:261-9.

14 Edwards K, Wenstone R. Successful resuscitation from recurrent ventricular fibrillation secondary to butane inhalation. Br J Anaesth 2000:84:803-5.

15 Gray M, Lazarus J. Butane inhalation and hemiparesis. Clin Toxicol 1993;31:483-5. 


\title{
Hyperthermia associated with central anticholinergic syndrome caused by a transdermal hyoscine patch in a child with cerebral palsy
}

\author{
A Frampton, J Spinks
}

Emerg Med J 2005;22:678-679. doi: 10.1136/emj.2003.011254

$\mathrm{P}$ atients frequently present to the Emergency Department with elevated body temperature; the distinction between "fever" and "hyperthermia" is vital. Many commonly prescribed drugs can cause hyperthermia. ${ }^{1}$ The goal of treatment is to reduce core temperature and oxygen demand before organ damage occurs. ${ }^{2}$ We present the case of a 14 year old boy who presented with hyperthermia due to a transdermal hyoscine patch used to control his symptoms associated with cerebral palsy.

\section{CASE}

A 14 year old boy with spastic quadriplegia presented to the Emergency Department (ED) having been found unresponsive at home in the early hours of the morning. On arrival in the ED he was drowsy and agitated with dilated but reactive pupils and a fever of $42^{\circ} \mathrm{C}$. His heart rate was $120 / \mathrm{min}$, blood pressure 100/70 and capillary refill time instant. No rash or neck stiffness was present but it was noted that despite the high fever he was not sweating and he had dry mucous membranes. The presence or absence of urinary retention was not commented on at initial examination. Examination was otherwise unremarkable except for the presence of a gastrostomy feeding tube and a hyoscine patch sited on the skin behind his ear to control oropharyngeal secretions, which was removed. His parents stated that he had been well the previous evening and had no other recent symptoms. The hyoscine patch was not a recent addition to his medication and no previous problems with its use were reported by the parents.

His temperature was rapidly reduced using paracetamol and fanning and following a $20 \mathrm{ml} / \mathrm{kg}$ bolus of fluid he became more responsive and his tachycardia settled. Two sets of blood cultures, urine, and sputum were sent for culture and broad spectrum antibiotics (a cephalosporin and metronidzole) were commenced. Lumbar puncture was not felt to be indicated immediately in the ED because of the initial rapid improvement (subsequent to the blood results being made available, LP was not undertaken because of the significant coagulopathy) and chest $x$ ray was unremarkable. He was transferred to the Paediatric High Dependency Unit for observation.

Over the course of the day he remained apyrexial. However, his urine output and mental state deteriorated and he became hypotensive. It became clear that he was developing multi-organ failure. He was transferred to the Paediatric Intensive Care Unit (PICU).

On PICU, he required invasive ventilation and cardiovascular support with moderate doses of adrenaline and noradrenaline. He developed rhabdomyolysis with a peak serum creatine kinase of 70,000U/l and myoglobinuria. He also developed anuric renal failure, for which he required continuous veno-venous haemofiltration for 7 days, and acute hepatic failure with a coagulopathy.

No source of sepsis was ever identified despite multiple sets of blood and sputum culture (including sputum for viral organisms) and his temperature remained below $38^{\circ} \mathrm{C}$. Antibiotics were stopped 72 hours after his admission to
PICU and his condition improved with supportive therapy alone. Urine was not sent for toxicology, however, he had no access to any drugs other than those prescribed to him and administered by his parents. In the absence of any proof of sepsis and in view of the pattern of deterioration in his condition we diagnosed multi-organ failure secondary to hyperthermia in association with central anti-cholinergic syndrome caused by the hyoscine patch. He made a full recovery.

\section{DISCUSSION}

Fever is an elevation of body temperature that exceeds the normal daily variation and occurs in conjunction with an increase in the hypothalamic set point. Hyperthermia, in contrast is characterised by an unchanged (normothermic) setting of the thermoregulatory centre in conjunction with an uncontrolled increase in body temperature that exceeds the body's ability to lose heat. Heat exposure, increased endogenous heat production (vigorous exercise, malignant hyperthermia) and decreased heat loss (over wrapping in blankets, anticholinergic medications) may precipitate hyperthermia. ${ }^{1}$

The primary injury in hyperthermia is due to cellular toxicity of temperatures above $42^{\circ} \mathrm{C}$. Above this temperature cell function deteriorates due causing widespread damage to all the major organ systems. ${ }^{3}$ The primary goal of treatment is rapid cooling either by evaporative or direct thermal methods. ${ }^{1}$

Central anticholinergic syndrome (CAS) is a potentially life-threatening syndrome caused by toxicity from a variety of drugs with anticholinergic effects, most notably atropine and hyoscine. ${ }^{4}$ It is produced by the inhibition of cholinergic neurotransmission at muscarinic receptor sites centrally or peripherally. Central nervous system manifestations range from an agitated or excitatory state with hyperthermia to a state of extreme depression with decreased respiratory drive or coma. ${ }^{5}$ Peripheral manifestations include sinus tachycardia, anhydrosis, functional ileus, urinary retention, hypertension, tremulousness, and myoclonic jerking. ${ }^{6}$ Hyperthermia, which is a feature in over $25 \%$ of cases, ${ }^{7}$ can be caused by the central action of the drug in combination with absence of sweating which raises the temperature further. Common signs and symptoms may be remembered by the mnemonic "red as a beet, dry as a bone, blind as a bat, mad as a hatter and hot as a hare". CAS has been reported following intentional overdose, inadvertent ingestion, geriatric polypharmacy and an idiosyncratic reaction to drugs with anticholinergic properties. $^{8}$ Systemic effects have been reported with topical eye drops. ${ }^{9}$

This case has been reported to the committee for safety of medicines using the yellow card reporting system and to the authors' knowledge this is the first report in the literature of CAS occurring as a result of a transdermal hyoscine patch in a child with cerebral palsy. The authors are aware of two other cases occurring in different centres; unfortunately the information is anecdotal only and no details of these cases are available to us. The only previous case report of CAS in a child we have been able to find is that of a 9 year old boy who 
developed CAS secondary to a transdermal hyoscine patch after an anaesthetic. ${ }^{10}$

No specific diagnostic studies exist for anticholinergic syndrome and serum drug concentrations are not helpful and rarely available to aid in the initial management. The antidote for anticholinergic toxicity is physostigmine salicylate. However, this drug has potentially serious cardiac side effects and is no longer recommended for use.

Prolonged hyperthermia may lead to devastating multiorgan failure and rapid cooling is essential to reduce the damage caused by excessively high temperatures. CAS has been previously well recognised in the elderly, but has rarely reported in children. Hyoscine patches are commonly used to control symptoms in children with cerebral palsy, often to good effect. The possibility of this syndrome, however, should be considered in any child on anticholinergic medications with a fever or the other symptoms described, particularly in the absence of sweating.

\section{Authors' affiliations}

A Frampton, J Spinks, Paediatric Intensive Care Unit, Southampton General Hospital, UK
Correspondence to: A Frampton, Paediatric Intensive Care Unit, Southampton General Hospital, Southampton, UK; anneframpton2003@yahoo.co.uk

Accepted for publication 15 March 2004

\section{REFERENCES}

1 Curley FJ, Irwin RS. Disorders of temperature control: Hyperthermia. Ch. 72. Intensive care Medicine, $4^{\text {th }}$ Ed. Irwin R Cerra F Rippe J 844-854.

2 Forester D. Fatal drug induced heat stroke. JACEP 1978;7(6):243-4

3 McElroy CR. Update on heat illness. Top Emerg Med 1980;2:1.

4 Torline RL. Extreme hyperpyrexia associated with central anticholinergic syndrome. Anesthesiology 1992;76:470-1.

5 Granacher RP, Baldessarine RJ, Messner E. Physostigmine treatment of delirium induced by anticholinergics. Am Fam Physician 1976; 13:99-103

6 Ferm R. Anticholinergic poisoning. Ch 132. Intensive Care Medicine, 4th Ed. Irwin R Cerra F Rippe J 1511-1514.

7 Greenblatt DJ, Shader RI. Drug Therapy: Anticholinergics. NEJM 1973;288:1215-19.

8 Schneck HG, Rupreht J. Central anticholinergic syndrome(CAS) in anaesthesia and intensive care. Acta Anaesthesiol Belg 1989;40:219-228.

9 Reid D, Fulton JD. Tachycardia precipitated by topical homatropine. Br Med J 1989:299:795.

10 Holland MS. Central anticholinergic syndrome in a paediatric patient following transdermal scopolamine patch placement. Nurse Anaesth 1992;3(3):121-4.

\section{Cardiovascular complications induced by cannabis smoking: a case report and review of the literature}

\section{B A C Fisher, A Ghuran, V Vadamalai, T F Antonios}

Emerg Med J 2005;22:679-680. doi: 10.1136/emj.2004.014969

Cannabis is generally considered a drug of low toxicity. Although attention has focused on its neuropsychiatric effects, little has been given to cardiovascular side effects. Here we report a case of atrial tachyarrhythmias following cannabis use, and review the literature on its cardiovascular effects and complications.

$\mathrm{C}$ annabis is generally considered a drug of low toxicity. Despite this a variety of cardiovascular complications have been documented. Here we report a case of atrial tachyarrhythmias and review the literature.

A 35 year old Afro-Caribbean female presented with a 1 month history of headaches and was found to be hypertensive with a sitting blood pressure of $179 / 119 \mathrm{mmHg}$ on average. Her past medical history included polycystic ovary disease. She smoked 20 cigarettes a day and had a history of infrequent cannabis use although none in the year preceding presentation. She denied using any other recreational drugs and was on no regular medication. There was a positive family history of essential hypertension. Clinical examination was unremarkable. She was admitted to hospital for further investigations particularly to rule out secondary hypertension.

Laboratory investigations showed normal urine analysis, biochemistry, thyroid function tests, plasma aldosterone/ renin ratio, and 24 hour urinary catecholamines. Abdominal CT scan was normal. A 12-lead electrocardiogram (ECG) suggested left ventricular hypertrophy using the Sokolow and Lyon voltage criteria ( $\mathrm{R}$ in $\mathrm{V} 5+\mathrm{S}$ in $\mathrm{Vl} \geqslant 35 \mathrm{~mm}$ ), however, the patient was slim built. An echocardiogram showed normal ventricular wall thickness and cavity size, good biventricular function, and normal transmitral inflow Doppler profile and atrial dimensions.

The patient was started on amlodipine tablets $10 \mathrm{mg}$ once daily and her blood pressure improved to $159 / 107 \mathrm{mmHg}$. Whilst in hospital, she smoked cannabis, and approximately 20-30 minutes later she developed palpitations, chest pain, and shortness of breath. Her blood pressure was found to be elevated at $233 / 120 \mathrm{mmHg}$ with a pulse rate of 150 beats per minute. An ECG showed a narrow complex tachycardia, which was confirmed as typical atrial flutter with 2:1 atrioventricular block, following the administration of intravenous adenosine. The cardiac rhythm shortly degenerated into atrial fibrillation at a rate of 146 beats/minute. She was treated with intravenous flecanide to relieve significant discomfort and sinus rhythm was promptly restored. Cardiac troponin at 12 hours was normal. Urine toxicology was positive for cannabis but no other recreational drugs were detected. Two weeks post discharge her blood pressure was $117 / 85 \mathrm{mmHg}$ on amlodipine $10 \mathrm{mg}$ once daily and atenolol $25 \mathrm{mg}$ once daily. A 24 hour ECG Holter monitoring demonstrated normal sinus rhythm. She remains well with excellent blood pressure control and has not smoked cannabis since.

\section{DISCUSSION}

The arrhythmogenic potential of cannabis smoking has rarely been reported. It is likely that the real incidence of arrhythmias is substantially underreported given the prohibition of cannabis use. Epidemiological data indicate that cannabis users are significantly more likely to experience palpitations with the majority being dose related sinus tachycardia. $^{12}$ Other reported arrhythmias include sinus 
bradycardia, second-degree atrioventricular block and atrial fibrillation..$^{3-5}$ The onset of arrhythmias can begin within a few minutes of smoking cannabis, reaching a peak within 30 minutes, but can persist for longer than 90 minutes. ${ }^{1}$ The cardiovascular effects of cannabis are largely related to its biphasic effect on the autonomic nervous system. ${ }^{6}$ At low or moderate doses, the drug leads to an increase in sympathetic activity and a reduction in parasympathetic activity, producing a tachycardia and increase in cardiac output. Blood pressure therefore increases. At high doses, sympathetic activity is inhibited and parasympathetic activity increased, leading to bradycardia and hypotension. Animal data suggests that the bioactive constituent of cannabis may cause sympathetic inhibition via $\mathrm{CBl}$ receptors on the presynaptic nerve terminals of postganglionic sympathetic fibres. $^{7}$ The influence of the autonomic nervous system in relation to the mechanism of atrial fibrillation has been previously examined. ${ }^{8}$ Both sympathetic and parasympathetic mechanisms have been implicated.

Vagal stimulation reduces action potential duration, shortens the atrial refractory period and produces cellular hyperpolarisation. ${ }^{8}$ The net result is a reduction in the wavelength of atrial activation, predisposing to the re-entrant mechanism of atrial fibrillation. ${ }^{8}$ Vagal induced atrial fibrillation is usually seen in hearts with no obvious structural disease. Adrenergic stimulation reduces action potential duration and alters the electrophysiological characteristics of the atria, favoring automaticity, triggered activity and micro-re-entry. Adrenergic mediated atrial fibrillation is usually seen in patients with structural heart disease often with a triggering event such as drugs, sepsis, or post operatively. Our patient, who used cannabis infrequently, may have had adrenergic induced atrial flutter. The heightened sympathetic response following cannabis use may have destabilized the arrhythmogenic substrate, in this case a hypertensive atrium, initiating atrial flutter. Adenosine, which shortens atrial refractory period, may have been the trigger that induced atrial fibrillation.

Evidence-based guidance for the management of cannabis induced atrial tachyarrhythmias is limited to case reports, ${ }^{34}$ but some general principles can be used to guide treatment. Haemodynamically unstable patients require prompt DC cardioversion. In haemodynamically stable patients a period of observation is recommended as the majority of these arrhythmias usually spontaneously revert to sinus rhythm. If the arrhythmia persists then the usual management protocols, as recommended by the American College of Cardiology/ American Heart Association and the European Society of Cardiology,' should be followed. Class la antiarrthymic agents (flecainide and propanofone) can be used to terminate these arrhythmias in structurally normal hearts.

Cannabis use has also been associated with premature ventricular contractions, ${ }^{1}$ and other reversible ECG changes affecting the $\mathrm{P}$ and $\mathrm{T}$ waves, and the ST segments. ${ }^{6}$ Although it is not clear if these changes are related to drug ingestion independent of effects on heart rate.
In patients with ischaemic heart disease, cannabis increases the frequency of anginal symptoms at low levels of exercise, ${ }^{10}$ owing to an increase in heart rate and myocardial contractility, and a reduction in the oxygen carrying capacity of blood due to the formation of carboxyhaemoglobin. ${ }^{11}$ These adverse haemodynamic changes may trigger plaque rupture in vulnerable individuals culminating in myocardial infarction, ${ }^{11}$ and sudden cardiovascular death. ${ }^{12}$ Myocardial infarction has also been reported in the presence of normal coronary arteries, suggesting coronary vasospasm. ${ }^{12}$ Other reported cardiovascular effects associated with cannabis consumption include transient ischaemic attacks and strokes. ${ }^{12}$

These recent reports confirm that cannabis use alone can result in cardiovascular complications. Furthermore, cannabis may often be used in combination with other recreational drugs such as cocaine and amphetamines, which may have synergistic cardiovascular effects. ${ }^{6}$ A careful recreational drug history should always be elicited, particularly when associated with unusual cardiovascular presentations and altered mental states.

\section{Authors' affiliations}

B A C Fisher, A Ghuran, V Vadamalai, T F Antonios, Blood Pressure Unit, Department of Cardiac \& Vascular Science, St George's Hospital Medical School, Cranmer Terrace, London SW17 ORE

Correspondence to: Dr B Fisher, Dept of Rheumatology, Charing Cross Hospital, Fulham Palace Road, London W6 8RF, UK;

bacfisher@yahoo.com

Accepted for publication 1 April 2004

\section{REFERENCES}

1 Johnson S, Domino EF. Some cardiovascular effects of marihuana smoking in normal volunteers. Clin Pharmacol Ther 1971;12:762-768.

2 Petronis KR, Anthony JC. An epidemiologic investigation of marijuanaand cocaine-related palpitations. Drug Alcohol Depend 1989;23:219-216.

3 Singh GK. Atrial fibrillation associated with marijuana use. Pediatr Cardiol 2000;21:284.

4 Kosior DA, Filipiak KJ, Stolarz P, et al. Paroxysmal atrial fibrillation following marijuana intoxication: a two-case report of possible association. Int J Cardiol $2001 ; 78: 183-184$.

5 Akins D, Awdeh MR. Marijuana and second-degree AV block. South Med J 1981;74:371-373.

6 Ghuran A, Nolan J. Recreational drug misuse: issues for the cardiologist. Heart 2000;83:627-33.

7 Kunos G, Jarai Z, Batkai S, et al. Endocannabinoids as cardiovascular modulators. Chem Phys Lipids 2000;108:159-168.

8 Coumel P. Paroxysmal atrial fibrillation: a disorder of autonomic tone? Eur Heart J 1994;15:9-16.

9 Fuster V, Ryden LE, Asinger RW, et al. ACC/AHA/ESC guidelines for the management of patients with atrial fibrillation. Circulation 2001;104:2118-2150.

10 Aronow WS, Cassidy J. Effect of smoking marihuana and of a high-nicotine cigarette on angina pectoris. Clin Pharmacol Ther 1975; 17:549-554.

11 Mittleman MA, Lewis RA, Maclure M, et al. Triggering myocardial infarction by marijuana. Circulation 2001;103:2805-9.

12 Bachs L, Morland $\mathrm{H}$. Acute cardiovascular fatalities following cannabis use. Forensic Sci Int 2001;124:200-203.

\section{CORRECTION}

In the case report titled, Left flank pain as the sole manifestation of acute pancreatitis: a report of a case with an initial misdiagnosis (Emerg Med J 2005;22:452-3) the affiliation for Dr Jiann-hwa Chen was incorrect. The correct affiliation is Department of Emergency Medicine, General Cathay Hospital-Taipei, Taiwan, ROC. 